Perspective

\title{
Calling for a new agenda for conservation science to create evidence- informed policy
}

\author{
David Christian Rose ${ }^{\mathrm{a}, *}$, Tatsuya Amano ${ }^{\mathrm{b}, \mathrm{c}, \mathrm{d}}$, Juan P. González-Varo ${ }^{\mathrm{b}, \mathrm{e}}$, Nibedita Mukherjee ${ }^{\mathrm{b}}$, \\ Rebecca J. Robertson ${ }^{\mathrm{f}}$, Benno I. Simmons ${ }^{\mathrm{b}}$, Hannah S. Wauchope ${ }^{\mathrm{b}}$, William J. Sutherland ${ }^{\mathrm{b}, \mathrm{g}}$ \\ ${ }^{a}$ School of Environmental Sciences, University of East Anglia, Norwich Research Park, Norwich NR4 7TG, UK \\ ${ }^{\mathrm{b}}$ Conservation Science Group, Department of Zoology, University of Cambridge, The David Attenborough Building, Pembroke Street, Cambridge CB2 3QZ, UK \\ ${ }^{\mathrm{c}}$ Centre for the Study of Existential Risk, University of Cambridge, 16 Mill Lane, Cambridge CB2 1SB, UK \\ ${ }^{\mathrm{d}}$ School of Biological Sciences, University of Queensland, Brisbane, 4072, Queensland, Australia \\ ${ }^{\mathrm{e}}$ Dept. Biología de Organismos y Sistemas, UMIB (CSIC-UO-PA), Universidad de Oviedo, Oviedo, Spain \\ ${ }^{\mathrm{f}}$ School of Biology, Manton 8.17, Faculty of Biological Sciences, University of Leeds, Leeds LS2 9JT, UK \\ ${ }^{\mathrm{g}}$ BioRISC, St Catherine's College, Cambridge CB2 1RL, UK
}

\section{A R T I C L E I N F O}

\section{Keywords:}

Coproduction

Evidence-based policy

Evidence-informed policy

Science communication

Science-policy

\begin{abstract}
A B S T R A C T
Improving the use of scientific evidence in conservation policy has been a long-standing focus of the conservation community. A plethora of studies have examined conservation science-policy interfaces, including a recent global survey of scientists, policy-makers, and practitioners. This identified a list of top barriers and solutions to evidence use, which have considerable overlap with those identified by other studies conducted over the last few decades. The three top barriers - (i) that conservation is not a political priority, (ii) that there is poor engagement between scientists and decision-makers, and (iii) that conservation problems are complex and uncertain - have often been highlighted in the literature as significant constraints on the use of scientific evidence in conservation policy. There is also repeated identification of the solutions to these barriers. In this perspective, we consider three reasons for this: (1) the barriers are insurmountable, (2) the frequently-proposed solutions are poor, (3) there are implementation challenges to putting solutions into practice. We argue that implementation challenges are most likely to be preventing the solutions being put into practice and that the research agenda for conservation science-policy interfaces needs to move away from identifying barriers and solutions, and towards a detailed investigation of how to overcome these implementation challenges.
\end{abstract}

\section{Introduction}

Conservationists have long been encouraged to play their part in linking science to policy decisions (Meffe and Viederman, 1995) and there is an extensive literature on conservation science-policy interfaces (e.g. Bertuol-Garcia et al., 2018; Evans et al., 2017; Marshall et al., 2017; Walsh et al., 2015; Young et al., 2014). We have seen a number of major conservation science-policy research projects, including SPIRAL ${ }^{1}$ (e.g. Sarkki et al., 2014; Young et al., 2014), and BESAFE ${ }^{2}$ (see special issue introduced by Bugter et al., 2018), as well as supranational initiatives to link science and policy, such as the Global Environment Outlook 6th Assessment (UNEP, 2019; Mukherjee et al., 2019), the Intergovernmental Panel on Biodiversity and Ecosystem Services (Perrings et al., 2011; Tengö et al., 2017) and the EKLIPSE mechanism (http://www.eklipse-mechanism.eu).

Research has found that the science-policy process is complex and messy (see e.g. Evans et al., 2017). Evidence is taken up into policy for many different reasons, including because it is framed persuasively and tells a good story (e.g. Rose, 2015), or because it chimes with a window of opportunity in which policy-makers are looking to solve a particular problem (e.g. Rose et al., 2017), or even as a result of one important policy individual championing a particular cause (see Kingdon, 2003). Evidence uptake is about more than getting information to the desk of a policy-maker; rather, it must be presented in a user-friendly, persuasive, and politically salient way (e.g. Rose et al., 2017).

Whilst we acknowledge that conservation policies ought to take into account a range of different factors, including stakeholder interests, lay knowledges, and values (see Raymond et al., 2010; Rose, 2018),

\footnotetext{
* Corresponding author.

E-mail address: david.rose@uea.ac.uk (D.C. Rose).

${ }^{1}$ Science-Policy Interfaces for Biodiversity: Research, Action, and Learning (https://cordis.europa.eu/project/rcn/95837/factsheet/en).

${ }^{2}$ Biodiversity and Ecosystem Services: Arguments for our future Environment (https://cordis.europa.eu/project/rcn/100181/reporting/en).
} 
increasing access to and use of scientific evidence is likely to contribute to improved decision-making for the species and habitats we wish to conserve. Studies continue to show a lack of evidence-informed policy in conservation, which can lead to bad decision-making for biodiversity (Sutherland and Wordley, 2017). One example of bad decision-making caused by lack of evidence use was the decision to invest further in bat gantries in the UK (to guide bats to fly high enough over roads to reduce mortality) at a cost of $£ 1$ million when studies had shown them to be ineffective (Sutherland and Wordley, 2017). Greater use of evidence thus increases the likelihood of making better decisions for biodiversity. For example, Sutherland (2019) showed that learning from evidence about the effectiveness of under-road tunnels for amphibian conservation (to prevent traffic squashing them) is essential for getting the design right in terms of length, diameter, the presence of water, and lighting. Walsh et al. (2015) also found that conservation managers (mainly from the UK, Australia and New Zealand) were much more likely to select effective conservation actions after reading synopses of evidence.

Although advice given in the literature about how to improve evidence uptake do not guarantee success in a messy, non-linear policy process (Evans et al., 2017), they do at least improve the chances that evidence will be integrated. We thus take the clear instrumental position in this paper that, as inter-disciplinary scientists seeking to improve evidence-informed policy-making, it is important to seek the best ways of enhancing evidence uptake.

We refer to three categories in this paper. Firstly, we discuss barriers to the use of evidence in policy, in other words factors which restrict the use of evidence in decision-making. Secondly, we refer to solutions to overcome these barriers. Lastly, we consider the implementation challenges preventing proposed solutions from being put into practice. We recognise that the literature can refer to both barriers and implementation challenges together - for example, lack of academic incentives to engage with policy has been talked about as a barrier to evidence and also as an implementation challenge to the solutions aimed at improving academic engagement with policy. However, we prefer to present each category as described above and use the list of top barriers described by Rose et al. (2018) before describing implementation challenges to the suggested solutions in the same paper.

The paper by Rose et al. (2018) is one of the most extensive in this literature. It gathered the views, in six different languages, of 758 academics, practitioners, and people in policy positions from 68 nations (Rose et al., 2018). The results were reported with optimism as it was the first global attempt to rank the importance of various barriers and solutions to evidence-informed policy and found widespread agreement on science-policy challenges between different groups of people and regions. ${ }^{3}$ The study identified ten major barriers to the use of scientific evidence in policy. These are grouped in this perspective into three themes: (1) conservation is not a short-term political priority, (2) limited or poor engagement between scientists and decision-makers reduces the quality of communication, and (3) conservation problems are complex and uncertain (Table 1). Top solutions highlighted to address each of these categories are also listed in Table 1 (from Rose et al., 2018).

In light of the empirical evidence presented by Rose et al. (2018), it is worth reflecting on whether progress is being made towards the objective of improving the use of scientific evidence in conservation policy. The same barriers and solutions have been identified by a decade's worth of sustained interest in conservation science-policy interfaces; yet, there are concurrent calls for a new research agenda in conservation which sets out to learn from 'bright spots' of evidence use in order to identify solutions to a lack of evidence-informed

\footnotetext{
${ }^{3}$ Agreement between scientists and policy-makers was similarly found by Bertuol-Garcia et al. (2018), which counters the received wisdom that academics and policy makers would disagree on the reasons preventing evidence use.
}

conservation policy (Cvitanovic and Hobday, 2018). Here, we question whether the research agenda at conservation science-policy interfaces should be focused on identifying solutions for improved evidence use, which are both widely known and repeated, or whether emphasis should be instead placed on overcoming the implementation challenges preventing the solutions from being put into action (Fig. 1).

\section{Lack of progress towards evidence-informed policy}

\subsection{The same barriers and solutions are being frequently identified}

The same barriers and solutions to evidence-informed conservation policy are being frequently identified and we critically evaluate these in section three. It is worth illustrating before this, however, how the same themes have re-occurred in the literature.

Using the categorisation of Table 1 as a guide, ecologists have long discussed the first barrier, that conservation is not a short-term political priority (Begon, 2017). Conservation is often seen as a long-term category of political concern that can easily be 'kicked down the road' and is rarely considered to be a top priority for the majority of the electorate (e.g. Lawton, 2007). Conservation issues are rarely mainstream in the media with high-profile meetings often occurring without the knowledge of mass audiences, with the exception of a few better publicised meetings (e.g. IPBES 7th session). A growing number of studies have also suggested the same solutions identified by Rose et al. (2018) including demonstrating the benefits of conserving biodiversity to both policy-makers and the general public. Good storytelling using politically salient frames have been proposed as a way of making conservation a policy priority (Bugter et al., 2018; Carmen et al., 2018; Mace, 2014; Rose, 2015; Rose et al., 2016), particularly if these stories can help seize a window of opportunity (Moon et al., 2014; Rose et al., 2017). The value of telling optimistic stories about the natural environment and improving science communication to the general public are also widely suggested (Balmford and Knowlton, 2017; see https:// conservationoptimism.org).

The issue of limited or poor engagement between scientists and decisionmakers (the second barrier) is also widely highlighted. Many studies have looked at the so-called 'gap' between conservation scientists and policy-makers (Shanley and López, 2009; Spierenburg, 2012; Turnhout et al., 2008), described in one study as an 'abyss' (Azevedo-Santos et al., 2017). This separation can lead to difficulties in communicating evidence and prevents the maintenance of a two-way dialogue (BertuolGarcia et al., 2017; Sarkki et al., 2014; Young et al., 2014). Poor communication can enhance the chances of evidence being misinterpreted, particularly by non-specialist policy-makers (Rose and Parsons, 2015; Sutherland et al., 2013).

Research has also widely exposed the limited interaction between conservation scientists, practitioners, and other key stakeholders such as local communities (Barmuta et al., 2010; Cook et al., 2013; Hulme, 2014; Walsh et al., 2015), which contributes to lack of accessible evidence (Arlettaz et al., 2010; Stephenson et al., 2016), lack of involvement of stakeholders (Suskevics, 2019), or the production of science that is not relevant to practice (Milner-Guland et al., 2010). The challenges of undertaking good knowledge exchange are also widely documented (Cvitanovic et al., 2015, 2016; Marshall et al., 2017; Nguyen et al., 2017).

The same solutions to this are frequently identified. The many papers cited above suggest that greater collaboration is needed between scientists and decision-makers. Various forms of collaboration are encouraged to establish a two-way dialogue (Young et al., 2014), including co-location of academic staff and policy-makers (Cvitanovic et al., 2015), stakeholder mapping to engage key actors (Colvin et al., 2016; Cvitanovic et al., 2016), and the greater use of either knowledge brokers/boundary organisations (e.g. NGOs) to help communicate across the science-policy divide (Bednarek et al., 2018; Brooke, 2008; Cvitanovic et al., 2015; Marshall et al., 2017; Posner and Cvitanovic, 
Table 1

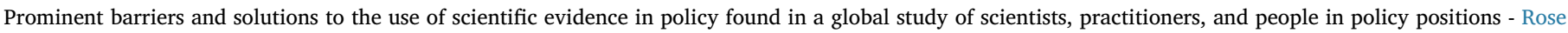

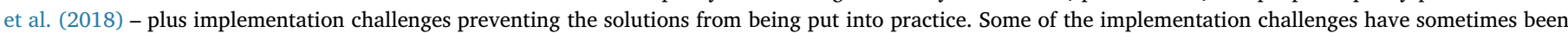

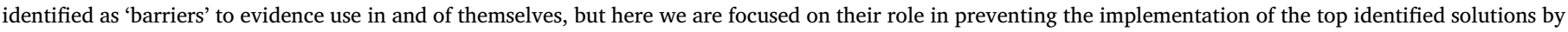
Rose et al. (2018).

\begin{tabular}{|c|c|c|}
\hline Barriers to the use of evidence in policy & Highest rated solutions to solve the barriers & Implementation challenges \\
\hline Conservation is not a short-term political priority & $\begin{array}{l}\text { Demonstrate the benefits of conservation } \\
\text { Public science outreach } \\
\text { Different measures of prosperity other than GDP to be } \\
\text { adopted } \\
\text {. More long-term policy-making bodies }\end{array}$ & $\begin{array}{l}\text { Rigid governance practices and norms } \\
\text { Electorate do not prioritise the environment }\end{array}$ \\
\hline $\begin{array}{l}\text { Limited or poor engagement between scientists and } \\
\text { decision-makers reduces the quality of } \\
\text { communication }\end{array}$ & $\begin{array}{l}\text { More collaboration between scientists and decision- } \\
\text { makers } \\
\text { Use knowledge brokers }\end{array}$ & $\begin{array}{l}\text { - Lack of incentives and skills for academics to } \\
\text { engage well } \\
\text { - Lack of time and skills for policy-makers to engage } \\
\text {. Limited career opportunities for knowledge brokers }\end{array}$ \\
\hline Conservation problems are complex and uncertain & $\begin{array}{l}\text { Encourage trans-disciplinary research } \\
\text { Train scientists in science communication (presumably to } \\
\text { communicate uncertainty better) } \\
\text { - } \text { Embrace structured decision-making processes - } \\
\text { additional important solution not mentioned by Rose } \\
\text { et al., 2018\} }\end{array}$ & $\begin{array}{l}\text { Lack of academic incentive structures to learn } \\
\text { communication skills and to engage diverse } \\
\text { audiences } \\
\text { \{Challenges of adopting structured decision-making/ } \\
\text { adaptive governance (rigid governance practices)\} }\end{array}$ \\
\hline
\end{tabular}

\section{Evidence and policy are not interacting to create evidence- informed policy.}

a)<smiles>[3H]C[GeH2]C(Cl)(Cl)Cl</smiles>

Policy

b)

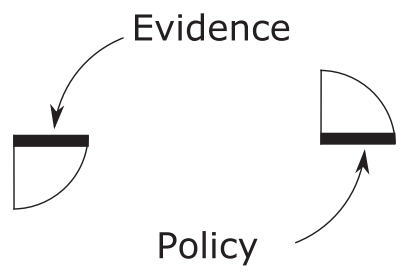

c)

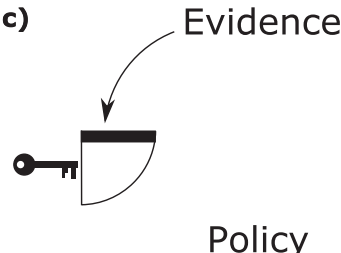

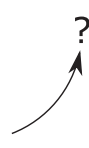

$?$
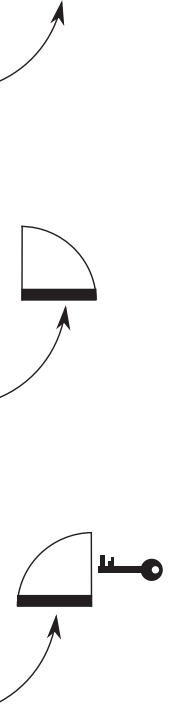

The barriers causing this are unknown.
The barriers (bars) have been identified (e.g. poor collaboration between scientists and decisions makers), but solutions are unknown.

\section{Evidence and policy are now interacting to create evidence-} informed policy.

d)

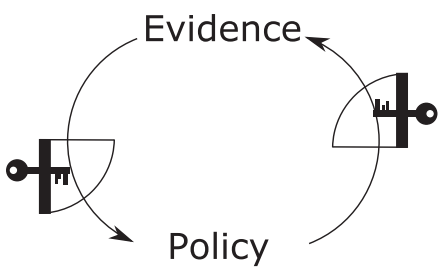
Policy
The solutions (keys) have been identified, but there are implementation challenges. (e.g. collaboration between scientists and decision makers should be increased, but academic incentive structures reward novelty, not policy impact.)
The solutions have been effectively implemented. (e.g. academic incentive structures now favour policy impact and projects designed in collaboration with policy makers.)

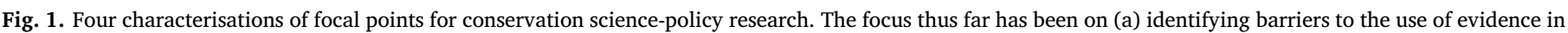

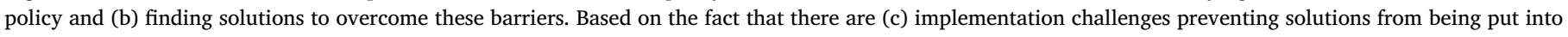
practice; we argue that the research agenda should focus on (d) overcoming implementation challenges. 
2019). Furthermore, The British Ecological Society in the UK conducts yearly legislative horizon scans of the forthcoming year to identify opportunities for influencing policy decisions. ${ }^{4}$ Increasingly, environmental scientists call for the co-production of knowledge between scientists and decision-makers (Lemos et al., 2018; Marshall et al., 2017; Wyborn, 2015), whilst other papers have described a similar process of closer engagement as 'translational ecology' (Chapin, 2017; Enquist et al., 2017).

Regarding the final barrier (conservation problems are complex and uncertain), many papers talk about the difficulty of conservation policymaking in a data void (Feeley and Silman, 2011; Game et al., 2014; Hughes et al., 2013). Policy-makers can sometimes struggle to make effective decisions when faced with uncertainty and this can be a reason for delaying a conservation decision in a situation where it might be politically more palatable to delay decision-making for later (Bradshaw and Borchers, 2000; Dovers et al., 1996; Lemos and Rood, 2010). Studies have focused on the need for improved science communication, particularly of uncertainty, and the need for specialist training of scientists, particularly early- or mid-career researchers (Cvitanovic et al., 2015; Evans and Cvitanonic, 2018; Rose and Parsons, 2015; Shanley and López, 2009). Training can focus on how to convey uncertainty to policy-makers in a more clear and transparent manner, which might overcome the perceived barrier of uncertain or complex conservation problems (Dovers et al., 1996). As for the suggestion of trans-disciplinary research to address complex problems, this has been proposed in various forms, including translational ecology and post-normal conservation science (Colloff et al., 2017; Rose et al., 2018).

\subsection{Moving beyond identification saturation}

If the same barriers are being found in the literature, and the same solutions proposed, we may not be making much progress. Thus, there is little merit in conducting more research with the purpose of identifying barriers and solutions since precedent implies that few, if any, novel findings would be generated. There may, however, be merit in further work to identify key solutions if it is focused on non-western contexts, since much of the literature is focused on Northern Europe, North America, Australia and New Zealand, and thus we may not yet fully understand how to improve evidence uptake in other areas.

The lack of apparent progress in moving beyond the same frequently suggested barriers and solutions could be as a result of three non-mutually exclusive reasons: (1) the top barriers are insurmountable, (2) proposed solutions are poor, (3) solutions have not been implemented properly. We acknowledge that there could be others - that there are solutions that have not yet been found (note point above about nonwestern contexts) or that implemented solutions have not yet had time to bear fruit - but the consistent agreement between research studies at conservation science-policy interfaces, backed by decades of research in the policy sciences, suggests this may be unlikely in those areas of the world in which considerable research has been conducted. We do acknowledge that it is often difficult to measure the impact of evidence on policy, as there are few 'direct hits' between science and decisions (Owens, 2015).

\section{Exploring reasons for lack of progress}

\subsection{Insurmountable barriers or bad solutions?}

Despite clear evidence that environmental problems, such as climate change and biodiversity loss, threaten human survival (UNEP, 2019), there can be little doubt that the environment as a category of political concern often fails to be prominent (barrier 1). Opinion polls have shown

\footnotetext{
${ }^{4}$ (https://www.britishecologicalsociety.org/policy/reports-publications/ legislative-scans/).
}

in the past that the majority of the electorate list other issues as more prominent in their election choice (Lawton, 2007), which influences the nature of the policies that receive government-level attention, although we note that this might be changing.

There are signs though that nature conservation is becoming a much more prominent vote-winning issue, ${ }^{5}$ which might encourage policymakers to pay more attention to it. Despite struggling with many traditional political issues, such as the economy, policy-makers in modern democracies are now paying more attention to the environment. In the UK, for example, the issues of plastic pollution in our oceans captured the imagination of global policy-makers after the BBC's 'Blue Planet II' series (UNEP, 2019). Other examples of policy and public support in conservation can be seen around the world, including local opposition to land reclamation for US military purposes in Okinawa, Japan ${ }^{6}$ (The Japan Times, 2018). Furthermore, a scientist referring to the Chinese Government's decision to protect coastal wetlands in the Yellow Sea, a region dominated by pro-infrastructure policies, claimed that the conservation 'message has reached the central government' (Stokstad, 2018).

There is also growing momentum behind research that links conservation efforts with the provision of vital ecosystem services, such as climate change mitigation (Nowak et al., 2013), improving air quality (Tallis et al., 2011), reducing the urban heat island effect (DecletBarreto et al., 2013), enhancing urban drainage (Bolund and Hunhammar, 1999) and providing outdoor spaces for social activities (Sullivan et al., 2004). There is increasing evidence for links between biodiversity and health (Lovell et al., 2014; Sandifer et al., 2015; Cox et al., 2017). In 2015, the UK Office of National Statistics adopted frequency of visits to green spaces as an indicator of child wellbeing (Natural England, 2015). Evidence provided by the BESAFE project (see Bugter et al., 2018) suggests that conservation can attract policy and public support when framed in a variety of salient ways, including benefit to humans, and optimistic messages might cut through more (Balmford and Knowlton, 2017). Whilst there are challenges in adoption of an optimistic dialogue that does not create complacency (Hornsey and Fielding, 2016), there is some evidence that saliently framed conservation discourses can cut through (Rose et al., 2017). This is a point, however, for which there may be limited evidence in conservation (Kidd et al., 2019).

Other suggested solutions to the problem of lack of prominence for conservation on the political agenda include adopting different measures of prosperity, such as Gross National Happiness or an environmental measure of success rather than Gross Domestic Product, and the suggestion to establish long-term environmental policy-making bodies. However, these may have less chance of succeeding in the short term. Long-term advisory or policy-making bodies are widely susceptible to political changes, perhaps influenced by a change of regime or financial climate, and many struggle to last for a long period of time (Owens, 2015). Furthermore, unless short-term democratic election cycles, which are a central foundation of modern democracies, are to be replaced, then it appears unlikely that short-termism in politics will disappear (Lawton, 2007). It seems far more profitable to make a sustained public case that conserving the natural world provides both short- and long-term benefits to society.

In the context of limited engagement between scientists and policymakers (barrier 2), there is a growing trend in the conservation sciencepolicy literature to talk about 'spaces' between scientists, policy-makers, and other stakeholders, rather than 'gaps' (Cvitanovic and Hobday, 2018; Toomey et al., 2017). However, whether we think of the position between scientists, policy-makers, and other key decision-

\footnotetext{
${ }^{5}$ https://www.carbonbrief.org/guest-post-rolls-reveal-surge-in-concern-inuk-about-climate-change.

${ }^{6}$ A petition aimed at the US Federal Government to stop this land reclamation has thus far attracted 211253 signatures (24/03/19).
} 
makers as a 'gap' or a 'space', the fundamentals of Gieryn's (1983) seminal paper on boundary work remain resolute. The worlds inhabited by scientists and non-scientists are different. Engagement and communication between scientists and decision-makers will always be challenging because doing science is different than making policy. There is a fluid boundary between them which is consistently reified by the 'boundary work' of both scientists and policy-makers who seek to demarcate each of their domains (Gieryn, 1983).

Yet, here again there is room for optimism. There are good examples of effective engagement between conservation scientists and a variety of stakeholders, including government policy-makers, practitioners, and local communities. Successes include the development of an Environmental Offsets policy in Australia (see Miller et al., 2015), which was highly collaborative and iterative and has now shaped environmental offsetting around the world (Cowie et al., 2018). Another success is the productive engagement of multiple stakeholders and policy-makers for marine conservation in Tai Timu Tai Pari (New Zealand; see Jarvis et al., 2015; Jarvis, 2016). Lastly, successful engagements between policy-makers and scientists have occurred in the EKLIPSE project, which has established a mechanism to link supply and demand for conservation evidence in Europe (http://www.eklipsemechanism.eu/).

There are now a variety of schemes that encourage conservation scientists to engage better with policy-makers, across research, policy and practice. Elliott et al. (2018) compiled a global database of 650 conservation capacity initiatives, although this suffers from geographical gaps in the availability of such initiatives. These schemes aim to build capacity for scientists and policy-makers to understand the constraints faced by both groups, whilst also encouraging participants to develop their engagement skills. Mechanisms include co-location of science or policy staff, short- or long-term fellowship positions, or shortterm shadowing of roles. These initiatives show that scientists and policy-makers can engage more closely with one another and thus the barrier preventing collaboration is not insurmountable.

Conservation problems are complex and uncertain (barrier 3). It is likely that conservation problems will always have an element of complexity or uncertainty so this barrier cannot ever be definitively removed (Newbold et al., 2016). Advances in conservation science will enable progress in reducing uncertainty, through the collection of more data and improved methodologies and models, but evidence will retain an element of uncertainty and this has been shown to be uncomfortable for some decision-makers (Lemos and Rood, 2010). Even the presence of more certain scientific information may not resolve uncertainty in the case of 'wicked' conservation problems [problems which have high stakes, and high uncertainty] (Stirling, 2010; Head and Alford, 2013). Indeed, 'too much science' or an 'excess of objectivity' can sometimes complicate issues further (Sarewitz, 2004).

Suggested solutions to the uncertainty problem in the Rose et al. (2018) paper included more trans-disciplinarity and better communication of science uncertainty. More trans-disciplinarity is unlikely to overcome the uncertainty problem in itself, but better communication of uncertainty through techniques such as scenario building and presenting data in the form of probabilities in a transparent manner may be beneficial (see e.g. IPCC reports; Budescu et al., 2009).

We suggest that an additional solution to the barrier of uncertainty might help to overcome it, which was not mentioned in the Rose et al. (2018) study. ${ }^{7}$ The process of structured decision-making has been illustrated to be a successful way of making decisions under uncertainty in conservation, including for amphibian conservation in the US $\left(\mathrm{O}^{\prime}\right.$ Donnell et al., 2017). This process encourages scientists, policy-makers, and other stakeholders (trans-disciplinarity) to work together on defining the problem to be investigated and then to construct shared objectives. Then, a range of options to achieve those objectives are

\footnotetext{
${ }^{7}$ And thus we insert it into Table 1 in brackets.
}

considered and the consequences of each are discussed using the best available information. Finally, honest discussion of trade-offs associated with each option is held before making the final decision ( $\mathrm{O}^{\prime}$ Donnell et al., 2017). Under an adaptive management approach, this final decision may be subject to change as the chosen option is implemented, which allows decision-makers to change course if an unwanted or unexpected result occurs.

\subsection{Implementation challenges: a waiting game or lack of effective action?}

We acknowledge that the lack of general progress towards evidenceinformed policy (aside from relatively isolated examples of success) could be caused by a lag time between action and results. In other words, work is being done to implement the solutions, but policy change is slow and unpredictable (Cairney, 2016; Owens, 2015) and impact can be diffuse. One other possible reason for lack of progress, however, is that identified solutions are not being put into practice; in other words, collaboration and trans-disciplinarity are not commonplace despite their obvious benefits, or governance structures and decision-making processes are not changing to be more long-term because steps are not being implemented to make them a reality. There must, therefore, be implementation challenges preventing the solutions from being put into practice (Fig. 1).

These challenges are associated with institutional arrangements that are not conducive to the implementation of proposed solutions, a fact which has been raised in previous investigations of how to bridge the gap between science and policy (e.g. Jarvis et al., 2015). The work of Clark et al. (2016) on knowledge governance can help us to understand how formal and informal institutional arrangements create 'rules of the games', which the authors argue govern social expectations about how public decisions should be made (see also Van Kerkhoff, 2014). The ways in which institutions are set up and operate, whether they are governments or research organisations, enable actors working within them to act in a certain way, whilst restricting their ability to act in other ways. The conservation literature has identified institutional arrangements that are not conducive to bridging the gap between science and policy, such as restrictions on scientists and policy-makers working more closely together (e.g. Cvitanovic et al., 2015; Evans and Cvitanonic, 2018; Jarvis et al., 2015), including through co-production (Sutherland et al., 2017). Despite some discussion of such implementation challenges in the conservation literature, there are few, if any, systematic attempts to learn how to overcome them. This is a point noted by Cvitanovic et al. (2018), who find little empirical guidance for how to create a university-based boundary organisation that can implement measures to encourage collaboration between scientists and policy-makers. Political science scholars in other disciplines have also noted a lack of empirical evidence on how to overcome practical implementation challenges, including those associated with co-production (Oliver et al., 2019).

We discuss some of the major challenges associated with putting each of the solutions identified in Table 1 into practice, suggesting the most important research questions and methods to guide this new research agenda. We note that there are likely to be other implementation challenges, but we present a number of key ones here. Specifically the implementation challenges are: (1) Existing governance practices, norms, and voting behaviour, (2) Lack of institutional arrangements for collaboration, (3) Practical challenges of co-production and trans-disciplinarity (overlap with two), and (4) Limited career opportunities for knowledge brokers. Overcoming these implementation challenges should be the focus of new research in this space as it will provide the keys to clear the pathway for putting solutions into practice.

\subsubsection{Existing governance practices, norms, and voting behaviour}

Conservation scientists recognise the need to engage publics in the conservation movement for several reasons, including fashioning a twoway dialogue so that scientists can learn from publics, but also to 
illustrate the short- and long-term importance of the environment and the need to maximise short-term political windows of opportunity (Rose et al., 2017). There are evidently considerable implementation challenges associated with calls for more long-term policy structures and timescales, since modern democracies have deeply embedded shortterm election cycles and hold an expectation that governments will regularly change. The power to change this is not substantially in the hands of the conservation community, although the benefits of longterm scientific advisory bodies could be continually stressed (see e.g. Owens, 2015). The necessary shift to embrace structured decisionmaking in policy settings is also not in the direct gift of the conservation community to provide, and such processes are generally not suited to fast-paced decision environments. Yet, we can develop clearer guides for policy-makers on how to undertake such decision exercises and find ways of developing these methods for time-intensive policy contexts. The ability to engage the electorate to enhance voting along environmental lines is, however, partially in the gift of the conservation movement and there are signs that the green vote is rising, particularly in Europe. We note, however, that convincing the public of the need to conserve biodiversity might not be enough to stem declines within an overarching capitalist system and its associated social, political, and structural inequalities (which drives biodiversity loss) (see e.g. Brockington et al., 2008) .

Further research in the following areas might be useful:

1. What are the best ways to involve different sections of the electorate to make the environment a priority?

2. What types of political systems encourage biodiversity conservation and are they achievable?

3. What are the pros and cons of different forms of environmental activism, such as the methods used by Extinction Rebellion?

4. How can we identify, create and use policy windows more effectively for evidence use?

5. Do differences between the values of conservation scientists enhance or restrict the impacts of conservation messaging (see Sandbrook et al., 2019)?

6. How do we facilitate institutional environments conducive for creation and continued existence of knowledge brokers?

7. How can structured decision-making work in fast-paced policy environments?

\subsubsection{Lack of institutional arrangements for collaboration}

Here we focus on the implementation challenges facing scientists, as these can be addressed by our community, rather than on the demandside challenges facing policy-makers. The perverse academic incentives to reward publication of novel research in high-profile journals, rather than policy impact has been discussed in many papers (Evans and Cvitanovic, 2018; Hulme, 2014; Keeler et al., 2017; Shanley and López, 2009). Although the impact agenda is becoming more prominent in academia, career progression is still often related to how much internationally-significant novel research an individual is producing. This research then ends up being published in outlets that are often inaccessible and/or not brought to the attention of policy-makers (Arlettaz et al., 2010; Walsh et al., 2015) and is also mostly available in English and therefore not in the local languages of non-English speakers (Amano et al., 2016). This can sideline the production of policy-relevant evidence and discourages academics from taking the time to learn communication skills and engage in sustained two-way dialogue with potential users of their research (Young et al., 2014). Thus, as a community of scientists interested in policy impact, even if we recognise the importance of engagement, it is often hard to do what we know needs to be done.

Encouraging more proactive engagement with policy-makers will need support. For example, the 2021 Research Excellence Framework in the UK has moved to impact case studies being given a weighting of $25 \%$ to the overall score which will stimulate policy impact activity from academics. But in the context of increased demands on academics' time, further institutional support from universities and funders is required to stimulate research that is likely to make a policy impact. There is a need for more universities to include policy impact and transdisciplinary collaboration in promotion criteria and to provide the time and support for staff to carry out these activities. Support is needed from funders for policy impact and to prioritise evidence synthesis and policy relevant science (Donnelly et al., 2018), rather than the continual production of novel evidence, and policy support staff are needed in academic institutions (Tyler, 2017). Evidence synthesis of what works in conservation is particularly valuable and this type of activity should be given significant credit in academic institutions (Sutherland et al., 2018).

More evidence is needed in the following areas:

1. To what extent are examples of good science communication and good policy engagement achievable across entire research institutions? (Oliver and Cairney, 2019 speculate that success stories are often the exception rather than the norm).

2. How can research institutions best employ and use policy support staff to support academics?

3. What package of incentives, from research institutions and funders, is needed to support policy impact work of conservation scientists?

4. Does a greater emphasis on policy impact restrict the quality and quantity of scientific advances?

5. Are different incentives and skill development packages needed for varying types of researcher and different career stages?

6. What is the best way to encourage publications to be open access?

These are just some of the questions that we argue need to be explored in the question to improve scientific engagement with policymakers. All require solutions to be implemented and then evaluated to see if there were challenges and whether policy impact improved.

\subsubsection{Practical challenges of co-production and trans-disciplinarity}

The phrases 'co-production' and 'trans-disciplinarity' are now regularly suggested as solutions to improve collaboration between scientists and stakeholders, including policy-makers. The former relates both to the co-creation of knowledge between scientists and stakeholders and to the establishment of a mutually trusting relationship (Miller and Wyborn, 2018), whilst the latter refers both to inter-disciplinarity within academic circles and the inclusion of non-academic stakeholders in projects. Both are frequently suggested without adequate discussion of the implementation challenges, although these are now being discussed more (see Polk, 2015; Sutherland et al., 2017; Lemos et al., 2018) especially in a wide-ranging paper by Oliver et al. (2019).

Long-term commitment is central to many of the collaborative relationships suggested by those who promote co-production or transdisciplinarity (Cvitanovic and Hobday, 2018; Lemos et al., 2018), but the practicality of this is challenged by a system that rewards a 'publishor-perish' model of research, or by the mobility of early- and mid-career researchers and the lack of policy institutional memory which precludes long-term relationships, and by the inevitably finite amount of resources (time and money) given to scientists to establish and maintain these relationships (Sutherland et al., 2017).

We argue that much more research is needed which critically evaluates the potential of co-production or trans-disciplinarity to work in practice. Questions may include:

1. When is co-production possible and when are other less resourceintensive forms of engagement more appropriate?

2. What impacts do co-productive processes have on scientific careers and policy impact?

3. How can institutions best support researchers to learn the skills and give the time needed to success in trans-disciplinary projects?

4. To what extent is co-production possible for policy-makers who 
must make decisions in time-poor policy venues?

5. What types of knowledge governance structures best enable transdisciplinarity? (see Clark et al., 2016; Van Kerkhoff, 2014 for some initial ideas)

Other interesting questions are posed by Oliver et al. (2019) who encourage more research on the 'dark-side' of, or implementation challenges associated with, co-production.

\subsubsection{Limited career opportunities for knowledge brokers}

Whilst better training of scientists in engagement skills is useful, there will be trustworthy, skilled boundary spanners who can act as skilled intermediaries between research and policy (Bednarek et al., 2018). Working with such individuals or boundary organisations, including charities, learned societies, will enable academics to benefit from their policy and public affairs expertise and resources, and to build the informal networks necessary for establishing credibility. Again, more work is needed to investigate the ideal incentives and structures needed to encourage academics to work with these organisations. But, further research is also needed on how to enhance the career of knowledge brokers and to set up structures enabling an effective exchange of knowledge between them and research institutions (Cvitanovic et al., 2018). Should research institutions, for example, contribute financially to the work of knowledge brokering organisations and what support is needed when researchers are undertaking placements in such organisations?

\section{Concluding remarks}

We have presented the case for a step change in the focus of research interested in conservation science-policy interfaces. Rather than setting out to identify barriers and solutions to the use of conservation science in policy, which are now widely documented, we should focus on overcoming implementation challenges preventing solutions from working. These generally relate to institutional arrangements which are not conducive to the implementation of closer collaboration, structured and long-term decision-making, or knowledge brokering activities. It is true that some of these institutional arrangements, particularly governance practices, norms, and voting behaviour are less in the control of the conservation community, although we can take action to influence others in making changes. Yet, many of the 'rules of the game' that prevent collaboration, including forms of co-production, occur within our own academic institutions and those connected to them (e.g. journals, funding). These institutional arrangements will not change unless we take more sustained action to implement many of the rules that allow closer collaboration, namely career progression criteria and incentives that reward engagement and good communication/evidence synthesis activities, prioritised funding of impactful, inter-disciplinary projects, and accessible open publishing for all. Keeler et al. (2017) invite the environmental science community to seize the opportunity of creating a new kind of academia suited to the society it serves and we invoke the spirit of their message to call for a new conservation-science policy agenda focused on implementation challenges, many of which are within our control.

\section{Acknowledgements}

DCR acknowledges the support of the University of East Anglia for supporting travel associated with this paper. WJS is funded by Arcadia. HSW is funded by a Cambridge Trust Cambridge-Australia Scholarship and a Cambridge Department of Zoology JS Gardiner Fellowship. BIS is supported by the Natural Environment Research Council as part of the Cambridge Earth System Science NERC DTP [NE/L002507/1]. RJR is supported by the Natural Environment Research Council as part of the Leeds-York SPHERES NERC DTP [NE/L002574/1]. TA acknowledges the Grantham Foundation for the Protection of the Environment, the
Kenneth Miller Trust, and an Australian Research Council Future Fellowship (FT180100354).

No competing interests.

\section{References}

Amano, T., Gonzalez-Varo, J.P., Sutherland, W.J., 2016. Languages are still a major barrier to global science. PLoS Biol. 14 (12), e2000933.

Arlettaz, R., Schaub, M., Fournier, J., Reichlin, T.S., Sierro, A., Watson, J.E.M., Braunisch, V., 2010. From publications to public actions: when conservation biologists bridge the gap between research and implementation. BioScience 60, 835-842.

Azevedo-Santos, V.M., Fearnside, P.M., Oliveira, C.S., Padial, A.A., Pelicice, F.M., et al., 2017. Removing the abyss between conservation science and policy decisions in Brazil. Biodivers. Conserv. 26 (7), 1745-1752.

Balmford, A., Knowlton, N., 2017. Why earth optimism? Science 356 (6335), 225.

Barmuta, L.A., Linke, S., Turak, E., 2010. Bridging the gap between 'planning' and 'doing' for biodiversity conservation in freshwaters. Freshw. Biol. 56 (1), 180-195.

Bednarek, A.T., Wyborn, C., Cvitanovic, C., Meyer, R., Colvin, R.M., et al., 2018. Boundary spanning at the science-policy interface: the practitioners' perspectives. Sustain. Sci. https://doi.org/10.1007/s11625-018-0550-9.

Begon, M., 2017. Mike Begon: winning public arguments as ecologists: time for a new doctrine? Trends in Ecology and Evolution 32 (6), 394-396.

Bertuol-Garcia, D., Morsello, C., El-Hani, C.N., Pardini, R., 2017. A conceptual framework for understanding the perspectives on the causes of the science-practice gap in ecology and conservation. Biol. Rev. 93 (2), 1032-1055.

Bertuol-Garcia, D., Morsello, C., El-Hani, C.N., Pardini, R., 2018. Shared ways of thinking in Brazil about the science-practice interface in ecology and conservation. Conserv. Biol. https://doi.org/10.1111/cobi.13242.

Bolund, P., Hunhammar, S., 1999. Ecosystem services in urban areas. Ecol. Econ. 29 (2), 293-301.

Bradshaw, G.A., Borchers, J.G., 2000. Uncertainty as information: narrowing the sciencepolicy gap. Ecol. Soc. 4 (1), 7.

Brockington, D., Duffy, R., Igoe, J., 2008. Nature Unbound: Conservation, Capitalism, and the Future of Protected Areas. Routledge, London.

Brooke, C., 2008. Conservation and adaptation to climate change. Conserv. Biol. 22 (6), 1471-1476.

Budescu, D.V., Broomell, S., Por, H.H., 2009. Improving communication of uncertainty in the reports of the intergovernmental panel on climate change. Psychol. Sci. 20 (3), 299-308.

Bugter, R., Harrison, P., Haslett, J., Tinch, R., 2018. Making a better case for biodiversity conservation: the BESAFE project. Biodivers. Conserv. https://doi.org/10.1007/ s10531-018-1543-9.

Cairney, P., 2016. The Politics of Evidence-Based Policy-Making. Palgrave Pivot, London, UK.

Carmen, E., Watt, A., Young, J., 2018. Arguing for biodiversity in practice: a case study from the UK. Biodivers. Conserv. (7), 1599-1617.

Chapin, F.S., 2017. Now is the time for translational ecology. Front. Ecol. Environ. 15 (10), 539.

Clark, W.C., van Kerkhoff, L., Lebel, L., Gallopin, G.C., 2016. Crafting useable knowledge for sustainable development. PNAS 113 (17), 4570-4578.

Colloff, M.J., Lavorel, S., van Kerkhoff, L.E., Wyborn, C.A., Fazey, I., Gorddard, R., et al., 2017. Transforming conservation science and practice for a postnormal world. Conserv. Biol. 31 (5). https://doi.org/10.1111/cobi.12912.

Colvin, R.M., Witt, G.B., Lacey, J., 2016. Approaches to identifying stakeholders in environmental management: insights from practitioners to go beyond the "usual suspects". Land Use Policy 52, 266-276.

Cook, C.N., Mascia, M.B., Schwartz, M.W., Possingham, H.P., Fuller, R.A., 2013. Achieving conservation science that bridges the knowledge-action boundary. Conserv. Biol. 27 (4), 669-678.

Cowie, A.L., Orr, B.J., Castillo Sanchez, V.M., et al., 2018. Land in balance: the scientific conceptual framework for land degradation neutrality. Environ. Sci. Pol. 79, 25-35.

Cox, D.T.C., Shanahan, D.F., Hudson, H.L., Fuller, R.A., Anderson, K., Hancock, S., Gaston, K.J., 2017. Doses of nearby nature simultaneously associated with multiple health benefits. Int. J. Environ. Res. Public Health 14, 172.

Cvitanovic, C., Hobday, A.J., 2018. Building optimism at the environmental sciencepolicy-practice interface through the study of bright spots. Nat. Commun. 9, 3466.

Cvitanovic, C., Hobday, A.J., van Kerkhoff, L., Wilson, S.K., Dobbs, K., Marshall, N.A., 2015. Improving knowledge exchange among scientists and decision-makers to facilitate the adaptive governance of marine resources: a review of knowledge and research needs. Ocean Coast. Manag. 112, 25-35.

Cvitanovic, C., McDonald, J., Hobday, A.J., 2016. From science to action: principles for undertaking environmental research that enables knowledge exchange and evidencebased decision-making. J. Environ. Manag. 183, 864-874.

Cvitanovic, C., Lof, M.F., Nortstrom, A.V., Reed, M.S., 2018. Building university-based boundary organisations that facilitate impacts on environmental policy and practice. PLoS One. https://doi.org/10.1371/journal.pone.0203752.

Declet-Barreto, J., Brazel, A.J., Martin, C.A., Chow, W.T.L., Harlan, S.L., 2013. Creating the park cool island in an inner-city neighborhood: heat mitigation strategy for Phoenix, AZ. Urban Ecosyst. 16 (3), 617-635.

Donnelly, C.A., Boyd, I., Campbell, P., Craig, C., Vallance, P., Walport, M., 2018. Four principles to make evidence synthesis more useful for policy. Nature 558, 361-364.

Dovers, S.R., Norton, T.W., Handmer, J.W., 1996. Uncertainty, ecology, sustainability and policy. Biodivers. Conserv. 5 (10), 1143-1167.

Elliott, L., Ryan, M., Wyborn, C., 2018. Global patterns in conservation capacity development. Biol. Conserv. 221, 261-269.

Enquist, C.A.F., Jackson, S.T., Garfin, G.M., et al., 2017. Foundations of translational ecology. Front. Ecol. Environ. 15 (10), 541-550.

Evans, M.C., Cvitanonic, C., 2018. An introduction to achieving policy impact for early 
career researchers. Palgrave Communications 4, 88.

Evans, M.C., Davilla, F., Toomey, A., Wyborn, C., 2017. Embrace complexity to improve conservation decision making. Nature Ecology \& Evolution 1, 1588

Feeley, K.J., Silman, M.R., 2011. The data void in modelling current and future distributions of tropical species. Glob. Chang. Biol. 17 (1), 626-630.

Game, E.T., Meijaard, E., Sheil, D., McDonald-Madden, E., 2014. Conservation in a wicked complex world; challenges and solutions. Conserv. Lett. 7 (3), 271-277.

Gieryn, T., 1983. Boundary-work and the demarcation of science from non-science: strains and interests in professional ideologies of scientists. Am. Sociol. Rev. 48, 781-795.

Head, B.W., Alford, J., 2013. Wicked problems: implications for public policy and management. Administration \& Society 47 (6), 711-739.

Hornsey, M.J., Fielding, K.S., 2016. A cautionary note about messages of hope: focusing on progress in reducing carbon emissions weakens mitigation motivation. Glob. Environ. Chang. 39, 26-34.

Hughes, T.P., Huang, H., Young, M.A.L., 2013. The wicked problem of China's disappearing coral reefs. Conserv. Biol. 27 (2), 261-269.

Hulme, P.E., 2014. EDITORIAL: bridging the knowing-doing gap: know-who, know-what, know-why, know-how and know-when. J. Appl. Ecol. 51 (5), 1131-1136.

Jarvis, R.M., 2016. Putting People Back in the Picture: A Social Research Agenda for a Social-Ecological Approach to Conservation. PhD Thesis. Auckland University of Technology.

Jarvis, R.M., Borrelle, S.B., Bollard Breen, B., Towns, D.R., 2015. Conservation, mismatch and the research implementation gap. Pac. Conserv. Biol. 21 (2), 105-107.

Keeler, B.L., Chaplin-Kramer, R., Guerry, A.D., Addison, P.F.E., Bettigole, C., Burke, I.C., Gentry, B., et al., 2017. Society Is Ready for a New Kind of Science - Is Academia?. Bioscience. https://doi.org/10.1093/biosci/bix051.

Kidd, L.R., Bekessy, S.A., Garrard, G.E., 2019. Neither Hope nor Fear: Empirical Evidence Should Drive Biodiversity Conservation Strategies. Trends in Ecology \& Evolution 34 (4), 278-282.

Kingdon, J., 2003. Agendas, Alternatives, and Public Policies, 2nd ed. Longman, New York, USA.

Lawton, J., 2007. Ecology, policy and politics. J. Appl. Ecol. 44, 465-474.

Lemos, M., Rood, R., 2010. Climate projections and their impact on policy and practice. Clim. Chang. 1, 670-682.

Lemos, M.C., Arnott, J.C., Ardoin, N.M., Baja, K., Bednarek, A.T., et al., 2018. To coproduce or not to co-produce. Nature Sustainability 1, 722-724.

Lovell, R., Wheeler, B.W., Higgins, S.L., Irvine, K.N., Depledge, M.H., 2014. A systematic review of the health and well-being benefits of biodiverse environments. Journal of Toxicology and Environmental Health - Part B: Critical Reviews 17 (1), 1-20.

Mace, G.M., 2014. Whose conservation? Science 345, 1558-1560.

Marshall, N., Adger, N., Attwood, S., Brown, K., Crissman, C., et al., 2017. Empirically derived guidance for social scientists to influence environmental policy. PLoS One 12 (3), e0171950

Meffe, G.K., Viederman, K., 1995. Combining science and policy in conservation biology. Wildl. Soc. Bull. 23, 327-332.

Miller, C., Wyborn, C., 2018. Co-production in global sustainability: histories and theories. Environ. Sci. Pol. https://doi.org/10.1016/j.envsci.2018.01.016.

Miller, K.L., Trezise, J.A., Kraus, S., et al., 2015. The development of the Australian environmental offsets policy: from theory to practice. Environ. Conserv. 42, 306-314.

Milner-Guland, E.J., Fisher, M., Browne, S., Redford, K.H., Spencer, M., Sutherland, W.J., 2010. Do we need to develop a more relevant conservation literature? Oryx 44 (1), 1-2.

Moon, K., Adams, V.M., Januchowski-Hartley, S.R., Polyakov, M., Mills, M., Bigg, D., Knight, A.T., Game, E.T., Raymond, C.M., 2014. A multidisciplinary conceptualization of conservation opportunity. Conserv. Biol. 28 (6), 1484-1496.

Mukherjee, N., Pascual, D.M., Davies, J., Gonçalves, L.R., Hills, J., McRae, L., et al., 2019. Chapter 13: biodiversity policy. In: UN Environment (2019). Global Environment Outlook - GEO-6: Healthy Planet, Healthy People, https://doi.org/10.1017/ 9781108627146. Nairobi.

Natural England, 2015. Children's visits to natural environments: new evidence. [online]. Available from: https://www.gov.uk/government/news/childrens-visits-to-naturalenvironments-new-evidence, Accessed date: 29 March 2019.

Newbold, T., Hudson, L.N., Arnell, A.P., Contu, S., De Palma, A., Ferrier, S., et al., 2016. Has land use pushed terrestrial biodiversity beyond the planetary boundary? A global assessment. Science 353 (6296), 288-291.

Nguyen, V.M., Young, N., Cooke, S.J., 2017. A roadmap for knowledge exchange and mobilization research in conservation and natural resource management. Conserv. Biol. 31 (4), 789-798.

Nowak, D.J., Greenfield, E.J., Hoehn, R.E., Lapoint, E., 2013. Carbon storage and sequestration by trees in urban and community areas of the United States. Environ. Pollut. 178, 229-236.

O' Donnell, K.M., Messerman, A.F., Barichvich, W.J., Semlitsch, R.D., Gorman, T.A., et al., 2017. Structured decision-making as a conservation tool for recovery planning of two endangered salamanders. J. Nat. Conserv. 37, 66-72.

Oliver, K. and Cairney, P. 2019. The dos and don't of influencing policy: a systematic review of advice to academics, Palgrave Communications 5, article number 21.

Oliver, K., Kothari, A., Mays, N., 2019. The dark side of coproduction: do the costs outweigh the benefits for health research? Health Research Policy and Systems 17, 33.

Owens, S., 2015. Knowledge, Policy, and Expertise: The UK Royal Commission on Environmental Pollution 1970-2015. Oxford University Press, Oxford, UK.

Perrings, C., Duraiappah, A., Larigauderie, A., Mooney, H., 2011. The biodiversity and ecosystem services science -policy Interface. Science 331, 1139-1140.

Polk, M., 2015. Transdisciplinary co-production: designing and testing a transdisciplinary research framework for societal problem solving. Futures 65, 110-122.
Posner, S., Cvitanovic, C., 2019. Evaluating the impacts of boundary-spanning activities at the interface of environmental science and policy: a review of progress and future research needs. Environ. Sci. Pol. 92, 141-151.

Raymond, C.M., Fazey, I., Reed, M.S., Stringer, L.C., Robinson, G.M., Evely, A.C., 2010. Integrating local and scientific knowledge for environmental management. In: Journal of Environmental Management 91,1766-77-183.

Rose, D.C., 2015. The case for policy relevant conservation science. Conserv. Biol. 29 (3), 748-754.

Rose, D.C., 2018. Avoiding a post-truth world: embracing post-normal conservation science. Conserv. Soc. 16 (4), 518-524.

Rose, N.A., Parsons, E.C.M., 2015. "Back off, man, I'm a scientist!" when marine conservation science meets policy. Ocean \& Coastal Management 115, 71-76.

Rose, D.C., Brotherton, P.M., Owens, S., and Pryke, T., 2016. Honest advocacy for nature: presenting a persuasive narrative for conservation. Biodivers. Conserv., http://dx.doi. org/https://doi.org/10.1007/s10531-016-1163-1.

Rose, D.C., Mukherjee, N., Simmons, B.I., Tew, E.R., Robertson, R.J., Vadrot, A.B.M., Doubleday, R., Sutherland, W.J., 2017. Policy windows for the environment: tips for improving the uptake of scientific knowledge. Environ. Sci. Pol. https://doi.org/10. 1016/j.envsci.2017.07.013.

Rose, D.C., Sutherland, W.J., Amano, T., González-Varo, J., Robertson, R.J., Simmons, B.I., et al., 2018. The major barriers and their solutions for evidence-informed conservation policy. Conserv. Lett. 11 (5), e12564.

Sandbrook, C., Fisher, J.A., Holmes, G., Luque-Lora, R., Keane, A., 2019. The global conservation movement is diverse but not divided. Nature Sustainability 2, 316-323.

Sandifer, P.A., Sutton-Grier, A.E., Ward, B.P., 2015. Exploring connections among nature, biodiversity, ecosystem services, and human health and well-being: opportunities to enhance health and biodiversity conservation. Ecosystem Services 12, 1-15.

Sarewitz, D., 2004. How science makes environmental controversies worse. Environ. Sci. Pol. 7, 385-403.

Sarkki, S., Niemelä, J., Tinch, R., van den Hove, S., Watt, A., Young, J., 2014. Balancing credibility, relevance and legitimacy: a critical assessment of trade-offs in sciencepolicy interfaces. Sci. Public Policy 41 (2), 194-206.

Shanley, P., López, C., 2009. Out of the loop: why research rarely reaches policy-makers and the public and what can be done. BIOTROPICA 41 (5), 535-544.

Spierenburg, M., 2012. Getting the message across: biodiversity science and policy interfaces- a review. Gaia 21 (2), 125-134.

Stephenson, P.J., Bowles-Newark, N., Regan, E., Stanwell-Smith, D., Diagana, M., et al., 2016. Unblocking the flow of biodiversity data for decision-making in Africa. Biol. Conserv. 213, 335-340.

Stirling, A., 2010. Keep it complex. Nature 468, 1029-1031.

Stokstad, E., 2018. China moves to protect coastal wetlands used by migratory birds. Science. https://www.sciencemag.org/news/2018/01/china-moves-protect-coastalwetlands-used-migratory-birds?r3f $986=$.

Sullivan, W.C., Kuo, F.E., Depooter, S.F., 2004. The fruit of urban nature: vital neighborhood spaces. Environ. Behav. 36 (5), 678-700.

Suskevics, M., 2019. Legitimate planning processes or informed decisions? Exploring public officials' rationales for participation in regional green infrastructure planning in Estonia. Environ. Policy Gov. https://doi.org/10.1002/eet.1836.

Sutherland, W.J., Spiegelhalter, D., Burgman, M., 2013. Policy: twenty tips for interpreting scientific claims. Nature 503, 335-337.

Sutherland, W.J., Wordley, C.F.R., 2017. Evidence complacency hampers conservation. Nature Ecology \& Evolution 1, 1215-1216.

Sutherland, W.J., 2019. Kaizen conservation? Oryx 53 (3), 397-398.

Sutherland, W.J., Shackelford, G., Rose, D.C., 2017. Collaborating with communities: coproduction or co-assessment? Oryx 51 (4), 569-570.

Sutherland, W.J., Dicks, L.V., Ockendon, N., Petrovan, S.O., Smith, R.K., 2018. What Works in Conservation. Open Book Publishers.

Tallis, M., Taylor, G., Sinnett, D., Freer-Smith, P., 2011. Estimating the removal of atmospheric particulate pollution by the urban tree canopy of London, under current and future environments. Landsc. Urban Plan. 103 (2), 129-138.

Tengö, M., Hill, R., Malmer, P., Raymond, C.M., Spierenburg, M., et al., 2017. Weaving knowledge systems in IPBES, CBD and beyond - lessons learned for sustainability. Curr. Opin. Environ. Sustain. 26-27, 17-25.

The Japan Times, 2018. Hawaiian activist with Okinawan roots is behind petition against Henoko base that garnered over 160,000 signatures. https://www.japantimes.co.jp/ news/2018/12/24/national/hawaiian-activist-okinawa-roots-behind-petitionhenoko-base-garnered-160000-signatures/\#.XJeeta2cbfY.

Toomey, A.H., Knight, A.T., Barlow, J., 2017. Navigating the space between research and implementation in conservation: research-implementation spaces. Conserv. Lett. 10 (5), 619-625.

Turnhout, E., Hisschemöller, M., Eijsackers, H., 2008. Ecological indicators: between the two fires of science and policy. Ecol. Indic. 7, 15-228.

Tyler, C., 2017. Wanted: academics wise to the needs of government. Nature 552, 7.

UN Environment, 2019. Global environment outlook - GEO-6: healthy planet. Healthy People. Nairobi. https://doi.org/10.1017/9781108627146.

Van Kerkhoff, L., 2014. Knowledge governance for sustainable development: a review. Challenges in Sustainability 1 (2), 82-93.

Walsh, J.C., Dicks, L.V., Sutherland, W.J., 2015. The effect of scientific evidence on conservation practitioners' management decisions. Conserv. Biol. 29 (1), 88-98.

Wyborn, C., 2015. Connecting knowledge with action through coproductive capabilities: adaptive governance and connectivity conservation. Ecol. Soc. 20 (1), 11.

Young, J.C., Waylen, K.A., Sarkki, S., Albon, S., Bainbridge, I., et al., 2014. Improving the science-policy dialogue to meet the challenges of biodiversity conservation: having conversations rather than talking at one-another. Biodivers. Conserv. 23, 387-404. 